\title{
Molecular cytogenetic characterisation of Elytrigia Xmucronata, a natural hybrid of $E$. intermedia and E. repens (Triticeae, Poaceae)
}

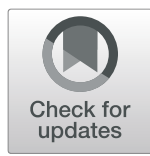

\author{
Ladislava Paštová $^{1,2^{*}} \mathbb{D}$, Alexander Belyayev ${ }^{1}$ and Václav Mahelka ${ }^{1}$
}

\begin{abstract}
Background: Interspecific hybridisation resulting in polyploidy is one of the major driving forces in plant evolution. Here, we present data from the molecular cytogenetic analysis of three cytotypes of Elytrigia xmucronata using sequential fluorescence (5S rDNA, $18 \mathrm{~S}$ rDNA and pSc119.2 probes) and genomic in situ hybridisation (four genomic probes of diploid taxa, i.e., Aegilops, Dasypyrum, Hordeum and Pseudoroegneria).

Results: The concurrent presence of Hordeum (descended from E. repens) and Dasypyrum + Aegilops (descended from E. intermedia) chromosome sets in all cytotypes of E. Xmucronata confirmed the assumed hybrid origin of the analysed plants. The following different genomic constitutions were observed for E. xmucronata. Hexaploid plants exhibited three chromosome sets from Pseudoroegneria and one chromosome set each from Aegilops, Hordeum and Dasypyrum. Heptaploid plants harboured the six chromosome sets of the hexaploid plants and an additional Pseudoroegneria chromosome set. Nonaploid cytotypes differed in their genomic constitutions, reflecting different origins through the fusion of reduced and unreduced gametes. The hybridisation patterns of repetitive sequences (5S rDNA, 18S rDNA, and pSc1 19.2) in E. Xmucronata varied between and within cytotypes. Chromosome alterations that were not identified in the parental species were found in both heptaploid and some nonaploid plants.

Conclusions: The results confirmed that both homoploid hybridisation and heteroploid hybridisation that lead to the coexistence of four different haplomes within single hybrid genomes occur in Elytrigia allopolyploids. The chromosomal alterations observed in both heptaploid and some nonaploid plants indicated that genome restructuring occurs during and/or after the hybrids arose. Moreover, a specific chromosomal translocation detected in one of the nonaploids indicated that it was not a primary hybrid. Therefore, at least some of the hybrids are fertile. Hybridisation in Triticeae allopolyploids clearly and significantly contributes to genomic diversity. Different combinations of parental haplomes coupled with chromosomal alterations may result in the establishment of unique lineages, thus providing raw material for selection.
\end{abstract}

Keywords: Allopolyploidy, Chromosomal alterations, Elymus repens, Higher polyploids, Hybridisation, FISH, GISH, Thinopyrum intermedium

\section{Background}

Hybridisation and polyploidisation are the major driving forces underlying plant evolution [1-4]. While hybridisation through genome merging may lead to the formation of new hybrid species, polyploidisation can stabilise hybrid breeding behaviour [5].

\footnotetext{
* Correspondence: ladislava.pastova@ibot.cas.cz

${ }^{1}$ Institute of Botany, Czech Academy of Sciences, Zámek 1, 25243 Průhonice, Czech Republic

${ }^{2}$ Department of Botany, Charles University, Benátská 2, 12801 Prague, Czech Republic
}

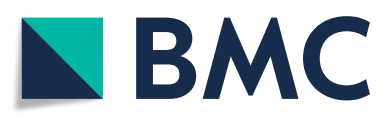

(อ) The Author(s). 2019 Open Access This article is distributed under the terms of the Creative Commons Attribution 4.0 International License (http://creativecommons.org/licenses/by/4.0/), which permits unrestricted use, distribution, and reproduction in any medium, provided you give appropriate credit to the original author(s) and the source, provide a link to the Creative Commons license, and indicate if changes were made. The Creative Commons Public Domain Dedication waiver (http://creativecommons.org/publicdomain/zero/1.0/) applies to the data made available in this article, unless otherwise stated. ploidy level (homoploid hybridisation) and between species of different ploidy levels (heteroploid hybridisation). In either case, the formation of new hybridogenous species in sympatry requires the presence of reproductive barriers between the hybrid and its parents. In the absence of reproductive barriers, newly formed hybrids can backcross with one or both parental species and form hybrid swarms [6].

The newly formed hybrid possesses a novel combination of genomes, which can manifest improved or enhanced 
qualities for certain characteristics (hybrid vigour or heterosis). However, hybrid vigour decreases in every subsequent generation of a hybrid's progeny because of the decreasing proportion of heterozygotes.

Allopolyploidisation, i.e., the multiplication of chromosome sets in hybrids, is a mechanism by which the decay of hybrid vigour can be avoided. In allopolyploids, the advantage of heterosis is largely retained due to the enforced pairing of homologous chromosomes and limited intergenomic recombination [1].

The involvement of unreduced gametes in mating is considered to be the prevailing mechanism for the origin of polyploids [7]. Alternative polyploid formation mechanisms include polyspermy (fertilisation by more male gametes; [8]) and (somatic) genome doubling [9]. Thus, the established allopolyploids can generate high ploidy level cytotypes in polyploid complexes.

The changes that occur after polyploid hybrid formation include diverse processes at the molecular, chromosomal, and organismal levels [10]. Coexistence of formerly isolated genomes is often followed by chromosomal restructuring, which contributes to genome variation beyond the merging of genomes [11].

The tribe Triticeae is an extensively studied group of grasses in which hybridisation and polyploidisation have significantly contributed to present-day diversity. Depending on the classification, Triticeae comprises approximately $350-500$ taxa in $27-37$ genera [12-14]. In total, 23 basic genomes were distinguished by Löve, who referred to them to as haplomes [13].

The basic chromosome number in Triticeae is $x=7$. The majority of species are allopolyploids, with ploidy levels ranging from tetraploid $(2 n=4 x)$ to dodecaploid $(2 n=12 x)$. The structure of the tribe is reticulate when certain haplomes are involved in the formation of more than one allopolyploid species [13].

Elytrigia ×mucronata (Opiz) Prokudin [syn. Agropyron mucronatum Opiz, E. apiculata (Tscherning) Jirásek], the subject of this study, is a natural hybrid between $E$. intermedia (Host) Nevski [syn. Elymus hispidus (Opiz) Melderis, Thinopyrum intermedium (Host) Barkworth \& D.R. Dewey] and E. repens (L.) Nevski [syn. Elymus repens (L.) Gould]. Both parental species occur predominantly as hexaploids $(2 n=6 x=42)$ in the study area (Czech Republic), but a minority nonaploid cytotype $(2 n=9 x=63)$ was recorded for E. repens $[15,16]$. Natural hybridisation between the hexaploids $E$. intermedia and E. repens appears to be common and is bi-directional, and evidence of backcrosses has been found [16]. Therefore, no obvious reproductive barriers exist in this species complex. In addition to the prevailing hexaploid $E$. xmucronata, hybrids with higher ploidy occur rarely, including heptaploids $(2 n=$ $7 \mathrm{x}=49$ ) in one population and nonaploids in three populations. The origin of the nonaploid hybrids has been assumed to have involved the fusion of unreduced and reduced gametes, where the unreduced gamete was donated by either of the parental species or their hybrid [16]. The origin of the heptaploids is unknown.

Both parental species are perennial allopolyploids with complex evolutionary histories [17-20]. The composition of the hexaploid Elytrigia repens genome is assumed to include two subgenomes originating from Pseudoroegneria (haplome symbol St) and one subgenome originating from Hordeum $(\mathrm{H})$ (genomic formula StStStStHH). In addition to the major genome constituents, the E. repens genome contains hints of other lineages from within and outside of Triticeae, demonstrating that the species must have acquired additional genetic material from distant sources $[17,18,21]$. A portion of the foreign genetic material found in $E$. repens has been inherited from its parental species [22].

The genomic constitution of the allohexaploid intermediate wheatgrass $E$. intermedia has not yet been satisfactorily resolved (for discussion, see [20, 23]). A consensus has been reached that the species is composed of three distinct subgenomes, one of which originated from Pseudoroegneria (St). The identity of the other two subgenomes remains controversial, particularly due to assumed contributions from Thinopyrum bessarabicum $\left(\mathrm{E}^{\mathrm{b}}\right)$, Th. elongatum (E $\left.{ }^{\mathrm{e}}\right)$, Dasypyrum (V), Secale (R), and Aegilops (D) [19, $20,23,24]$. In this respect, the presence of potential local varieties cannot be entirely excluded. Nevertheless, data from the analysis of native Central European specimens from the Czech Republic (from the same area from which the studied hybrids originated) clearly suggest contributions from Dasypyrum (V) and Aegilops (D) [19, 23]. Therefore, we concluded that these genera represent the donors of the two other subgenomes in this allopolyploid, and we therefore assume the genomic formula of $E$. intermedia to be StStDDVV.

Molecular cytogenetics techniques have given rise to new possibilities for studying the genomic constitution of hybrid plants. In particular, genomic in situ hybridisation (GISH) is suitable for studying the origins of allopolyploid species (e.g., [18, 25]). Moreover, both numerical and structural chromosomal alterations (especially intergenomic translocations) can be detected in allopolyploids [26, 27]. Furthermore, fluorescence in situ hybridisation (FISH) employing known repetitive sequences as chromosomal markers provides information on their physical localisation within the genome and allows us to study genome restructuring after polyploidisation events $[28,29]$.

In this study, we performed molecular cytogenetic analyses of three cytotypes of the allopolyploid hybrid $E$. $\times$ mucronata to characterise their genomic constitutions and elucidate their genome dynamics following hybrid formation. In particular, sequential GISH and FISH were employed to reveal (1) the genomic constitution of the 
hexaploid, heptaploid, and nonaploid cytotypes of $E$. xmucronata; (2) chromosomal alterations in the studied genotypes; and (3) the patterns of the ribosomal $5 \mathrm{~S}$ and $18 \mathrm{~S}$ rDNA units with the Triticeae-specific repeat pSc119.2, primarily with respect to their assignment to particular haplomes.

\section{Results}

Plant material for this study is available in previous studies $[15,16]$. The experiments were performed on two hexaploid $(2 n=6 x=42)$, two heptaploid $(2 n=7 x=49)$, and three nonaploid $(2 \mathrm{n}=9 \mathrm{x}=63)$ Elytrigia $\times$ mucronata plants from five Central European localities (Table 1, Fig. 1). While the hexaploid and nonaploid plants were used in previous studies focused on genome size variation and natural hybridisation $([15,16]$; for details see Methods Plant material), the heptaploids were studied for the first time in this paper. The plants were identified based on morphological, flow cytometric, and ITS diagnostic markers $[15,16]$.

\section{Hexaploid Elytrigia xmucronata Genome composition}

We analysed two hexaploid $(2 \mathrm{n}=6 \mathrm{x}=42)$ E. $\times$ mucronata plants. The plants $10-1$ and 17-4 originated from localities 'Paví vrch' and 'Vrbčany', respectively, (Table 1). After GISH, we observed identical hybridisation patterns in both analysed plants, which consisted of $21 \mathrm{St}$ (Pseudoroegneria) $+7 \mathrm{H}$ (Hordeum) $+7 \mathrm{D}$ (Aegilops) +7 $\mathrm{V}$ (Dasypyrum) chromosomes (Fig. 2a and c; Table 2). A signal was missing in the centromeric regions of Dasypyrum-labelled chromosomes. We are currently not convinced that this pattern is an indication of chromosomal translocations. In contrast, only one of the Hordeum-labelled chromosomes exhibited a Pseudoroegneria probe signal in the centromeric region, suggesting the presence of an intergenomic translocation (Figs. 2a, c and 3).

\section{Chromosomal structural variation}

In the plant 10-1, in which the complete set of FISH probes was applied, 5S rDNA, 18S rDNA and pSc119.2 signals were located on all of the chromosome sets (haplomes; Figs. 2b and 3; Table 2), with 9, 10 and 18 probe hybridisation sites being observed in this plant, respectively. Pseudoroegneria-labelled chromosomes (St haplome) carried five $5 \mathrm{~S}$ and four $18 \mathrm{~S}$ rDNA sites. The $5 \mathrm{~S}$ rDNA co-localised with $18 \mathrm{~S}$ rDNA on three chromosomes; on two of these chromosomes, the $5 \mathrm{~S}$ rDNA loci were situated proximal to $18 \mathrm{~S} \mathrm{rDNA}$, and on one of them, the $5 \mathrm{~S}$ rDNA locus was located distal to the $18 \mathrm{~S}$ rDNA. Additionally, there were two chromosomes carrying solitary subtelomeric 5S rDNA loci and a single chromosome carrying a subtelomeric $18 \mathrm{~S}$ rDNA locus. Within the Aegilops-labelled chromosomes (D haplome), we detected two chromosomes with co-localised $5 \mathrm{~S}$ and $18 \mathrm{~S}$ rDNA loci, where the latter was positioned distal to the former. The Hordeum-labelled chromosomes (H haplome) carried one $5 \mathrm{~S}$ rDNA site and three $18 \mathrm{~S}$ rDNA sites. On one of the chromosomes, there was a co-localised rDNA locus containing a double $18 \mathrm{~S}$ rDNA site with an intervening 5S rDNA site (18S-5S-18S). The V haplome, corresponding to Dasypyrum, carried single $5 \mathrm{~S}$ and $18 \mathrm{~S}$ rDNA sites located on separate chromosomes.

FISH with pSc119.2 revealed a disproportion compared to the number of detected sites (Fig. 2b; Table 2). The Pseudoroegneria-labelled chromosomes carried three pSc119.2 sites, one of which was located on the chromosome carrying the single $18 \mathrm{~S}$ rDNA locus on the opposite arm. A single pSc119.2 hybridisation site in the terminal region was detected within the Aegilops-labelled chromosomes. The $\mathrm{H}$ haplome from Hordeum carried three pSc119.2 loci. Two of these loci resided on chromosomes lacking rDNA sites, while the third was located within the co-localised rDNA locus. The seven Dasypyrum-labelled chromosomes carried eleven pSc119.2 hybridisation sites in total. Three of these chromosomes harboured $\mathrm{pSc} 119.2$ in both terminal

Table 1 List of the localities of the analysed plants

\begin{tabular}{|c|c|c|c|c|}
\hline \multirow[t]{2}{*}{ Locality (location, habitat) } & \multirow[t]{2}{*}{ Coordinates } & \multicolumn{3}{|c|}{ Ploidy levels/plant ID } \\
\hline & & $6 x$ & $7 x$ & $9 x$ \\
\hline $\begin{array}{l}\text { 1. Paví vrch ( } 2 \mathrm{~km} \mathrm{~S} \text { of Sedlec village, Paví vrch hill, steppe } \\
\text { and field margin) }\end{array}$ & $48^{\circ} 45^{\prime} 50.8^{\prime \prime} \mathrm{N} 16^{\circ} 41^{\prime \prime 33.1 " ~ E ~}$ & $10-1$ & & \\
\hline 2. Vrbčany (1.5 km NE of Vrbčany village, steppic slope) & $50^{\circ} 03^{\prime} 43.5^{\prime \prime} \mathrm{N} 14^{\circ} 59^{\prime} 56.0^{\prime \prime} \mathrm{E}$ & $17-4$ & & \\
\hline $\begin{array}{l}\text { 3. Čertoryje ( } 4 \text { km SE of Tvarožná Lhota village, Čertoryje } \\
\text { National Nature Reserve, mesophilous meadow) }\end{array}$ & 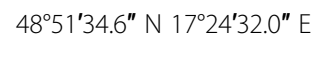 & & $C 9, C 25 B$ & \\
\hline $\begin{array}{l}\text { 4. Hovorany ( } 1 \mathrm{~km} N W \text { of Hovorany village, Hovoranské } \\
\text { louky Nature Reserve, steppic grassland) }\end{array}$ & $48^{\circ} 57^{\prime} 54.2^{\prime \prime} N 16^{\circ} 58^{\prime} 25.7^{\prime \prime} \mathrm{E}$ & & & $41-5$ \\
\hline $\begin{array}{l}\text { 5. Dolní Dunajovice ( } 0.8 \mathrm{~km} \text { W of Dolní Dunajovice village, } \\
\text { field margin) }\end{array}$ & 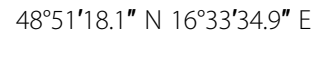 & & & $50-1,50-7$ \\
\hline
\end{tabular}




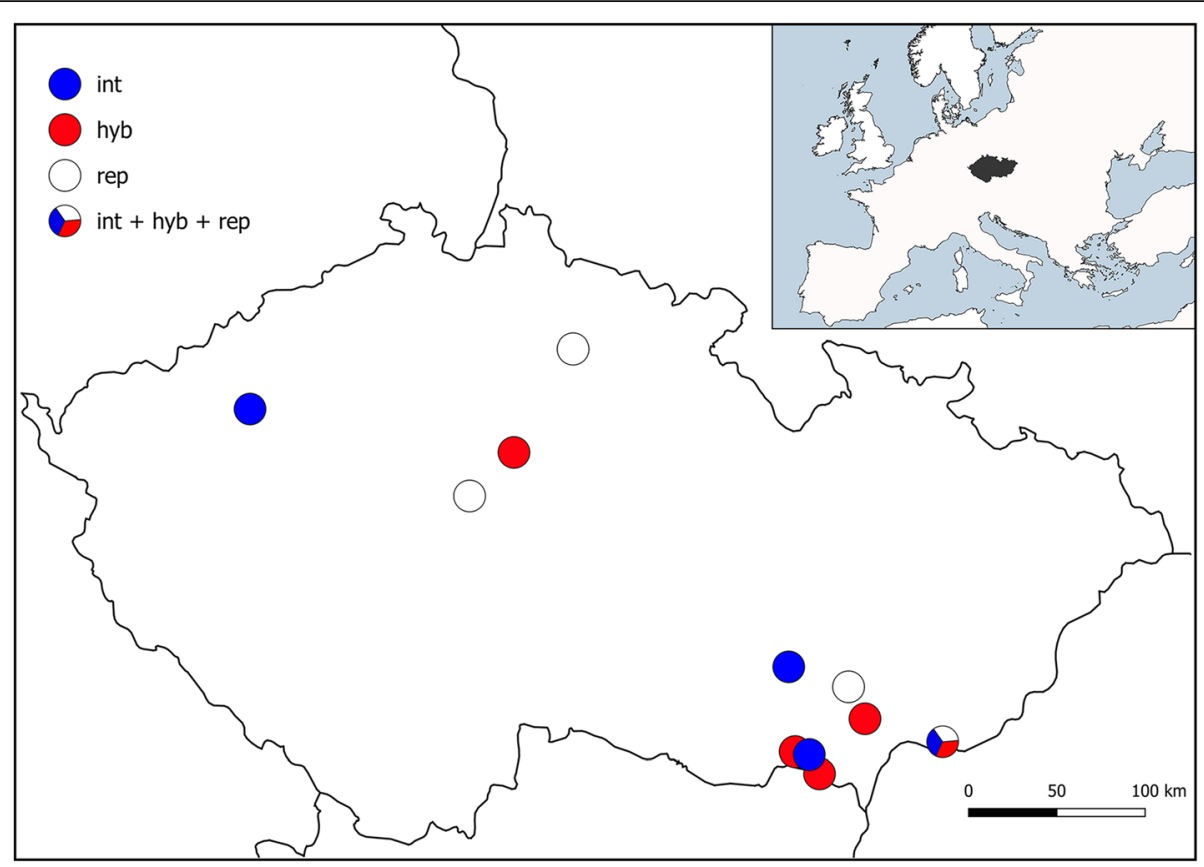

Fig. 1 Map showing the location of the studied plants of E. xmucronata. As complementary information, the locations of the parental species analysed in other studies (see text) is given. Blue circle (int) - Elytrigia intermedia; red circle (hyb) - E. xmucronata; empty circle (rep) - E. repens; combined circle (int + hyb + rep) - all three taxa originated from the locality
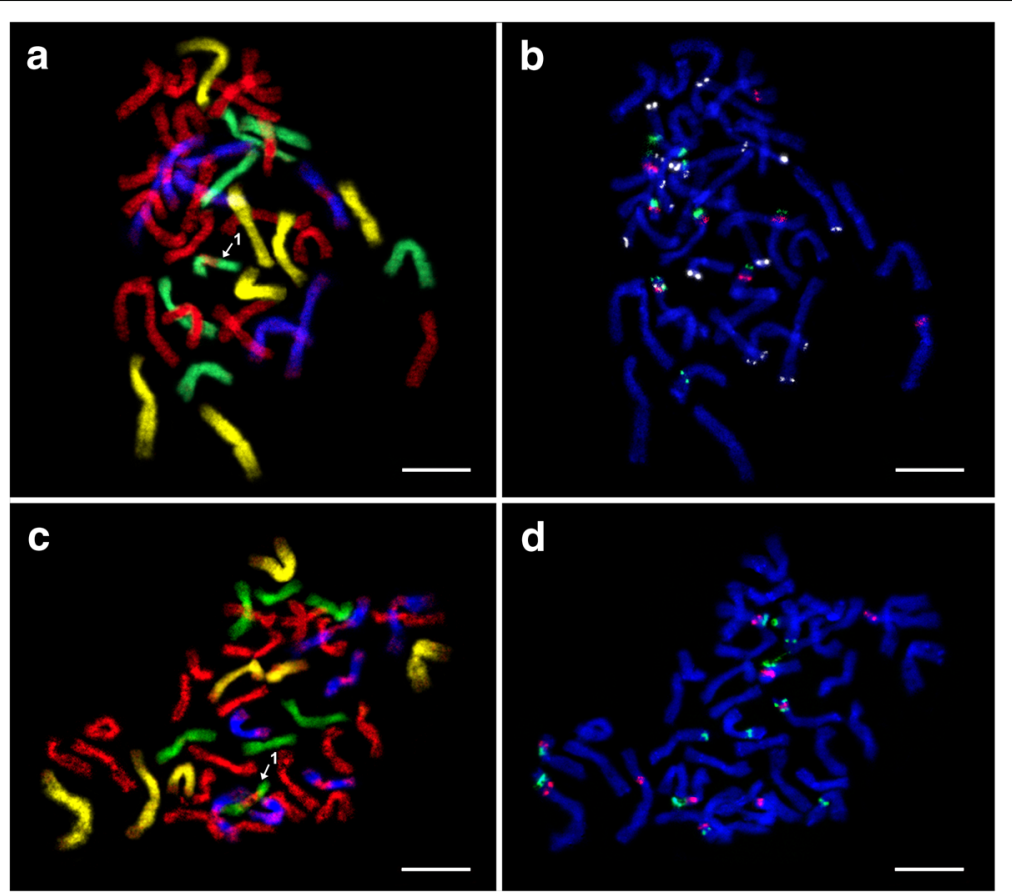

Fig. 2 Mitotic metaphase chromosomes of hexaploid E. Xmucronata after sequential FISH and GISH experiments. a and c GISH in plants 10-1 and 17-4: Aegilops tauschii (digoxigenin, anti-DIG-FITC, yellow pseudocolour), Dasypyrum villosum (biotin, streptavidin-Cy3, blue pseudocolour), Hordeum bogdanii (biotin, streptavidin-Cy3, green pseudocolour), and Pseudoroegneria spicata (Cy5, red). b and d FISH in plants 10-1 and 17-4: 5S rDNA (Cy5, red), 18S rDNA (digoxigenin, anti-DIG-FITC, green), and pSC119.2 (Cy3, white pseudocolour; applied only in 10-1 - b). After FISH, chromosomes were counterstained with DAPI. Structural chromosomal alterations are indicated by numerals (1). Scale bars $=10 \mu \mathrm{m}$ 
Table 2 Number of rDNA and pSc119.2 sites in E. xmucronata

\begin{tabular}{|c|c|c|c|c|c|c|c|c|}
\hline \multirow{2}{*}{\multicolumn{2}{|c|}{$\begin{array}{l}\text { Ploidy level/ } \\
\text { plant ID }\end{array}$}} & \multirow{2}{*}{$\begin{array}{l}\text { No. of chromosomes } \\
\text { of particular haplomes }\end{array}$} & \multicolumn{2}{|c|}{ Total no. of rDNA loci } & \multicolumn{3}{|c|}{ No. of co-localised rDNA loci } & \multirow{2}{*}{$\frac{\text { Total no. sites/chromosomes }}{\text { pSc119.2 }}$} \\
\hline & & & $5 S$ & 185 & $5 S-18 S^{1}$ & $18 S-5 S^{2}$ & $18 S-5 S-18 S^{3}$ & \\
\hline \multicolumn{9}{|c|}{$2 n=6 x=42$} \\
\hline $10-1$ & & & 9 & 10 & 1 & 4 & 1 & $18 / 14$ \\
\hline $17-4$ & & & 10 & 13 & 1 & 5 & 1 & - \\
\hline \multirow[t]{4}{*}{$10-1$} & St & 21 & 5 & 4 & 1 & 2 & 0 & $3 / 3$ \\
\hline & $\mathrm{D}$ & 7 & 2 & 2 & 0 & 2 & 0 & $1 / 1$ \\
\hline & $\mathrm{H}$ & 7 & 1 & 3 & 0 & 0 & 1 & $3 / 3$ \\
\hline & V & 7 & 1 & 1 & 0 & 0 & 0 & $11 / 7$ \\
\hline \multirow[t]{4}{*}{$17-4$} & St & 21 & 5 & 7 & 1 & 3 & 0 & - \\
\hline & $\mathrm{D}$ & 7 & 3 & 2 & 0 & 2 & 0 & - \\
\hline & $\mathrm{H}$ & 7 & 1 & 3 & 0 & 0 & 1 & - \\
\hline & V & 7 & 1 & 1 & 0 & 0 & 0 & - \\
\hline \multicolumn{9}{|c|}{$2 n=7 x=49$} \\
\hline $\mathrm{C} 25 \mathrm{~B}$ & & & 12 & 13 & 2 & 5 & 1 & - \\
\hline C9 & & & 11 & 12 & 2 & 4 & 1 & $14 / 11$ \\
\hline \multirow[t]{4}{*}{ C25B } & St & 28 & $8(+1)$ & $9(+2)$ & 2 & 3 & $1(+1)$ & - \\
\hline & $D$ & 7 & 3 & 2 & 0 & 2 & 0 & - \\
\hline & $\mathrm{H}$ & 7 & $0(-1)$ & $1(-2)$ & 0 & 0 & $0(-1)$ & - \\
\hline & V & 7 & 1 & 1 & 0 & 0 & 0 & - \\
\hline \multirow[t]{4}{*}{ C9 } & St & $27^{A-1}$ & $7(+1)$ & $8(+2)$ & 2 & 2 & $1(+1)$ & $3 / 3$ \\
\hline & $D$ & 7 & 3 & 2 & 0 & 2 & 0 & 0 \\
\hline & $\mathrm{H}$ & $8^{A+1}$ & $0(-1)$ & $1(-2)$ & 0 & 0 & $0(-1)$ & $2 / 2$ \\
\hline & V & 7 & 1 & 1 & 0 & 0 & 0 & $9 / 6$ \\
\hline \multicolumn{9}{|c|}{$2 n=9 x=63$} \\
\hline $50-1$ & & & 14 & 18 & 3 & 5 & 1 & $21 / 16$ \\
\hline $50-7$ & & & 11 & 16 & 3 & 4 & 1 & $20 / 15$ \\
\hline $41-5$ & & & 11 & 15 & 2 & 7 & 0 & $26 / 20$ \\
\hline \multirow[t]{4}{*}{$50-1$} & St & 35 & 9 & 9 & 2 & 3 & 0 & $4 / 4$ \\
\hline & $D$ & 7 & 2 & 3 & 0 & 2 & 0 & $1(-1) / 1$ \\
\hline & $\mathrm{H}$ & 14 & 2 & 5 & 1 & 0 & 1 & $6(+1) / 6$ \\
\hline & V & 7 & 1 & 1 & 0 & 0 & 0 & $10 / 5$ \\
\hline \multirow[t]{4}{*}{$50-7$} & St & 35 & 5 & 8 & 2 & 2 & 0 & $3 / 3$ \\
\hline & $D$ & 7 & 3 & 2 & 0 & 2 & 0 & $2 / 2$ \\
\hline & $\mathrm{H}$ & 14 & 2 & 5 & 1 & 0 & 1 & $5 / 5$ \\
\hline & V & 7 & 1 & 1 & 0 & 0 & 0 & $10 / 5$ \\
\hline \multirow[t]{4}{*}{$41-5$} & St & 28 & 4 & 7 & 1 & 3 & 0 & $7 / 7$ \\
\hline & D & 14 & 4 & 4 & 0 & 4 & 0 & 0 \\
\hline & $\mathrm{H}$ & 7 & 1 & 2 & 1 & 0 & 0 & $2 / 2$ \\
\hline & V & 14 & 2 & 2 & 0 & 0 & 0 & $17 / 11$ \\
\hline
\end{tabular}

${ }^{1} 18 \mathrm{~S}$ rDNA is situated proximal to the $5 \mathrm{~S}$ rDNA locus (the mutual position of the $5 \mathrm{~S}$ and $18 \mathrm{~S}$ rDNA loci on the chromosome in the direction from the centromere to the telomere)

${ }^{2} 18 S$ rDNA is situated distal to the 5 S rDNA locus

${ }^{3} 18 \mathrm{~S}$ rDNA is situated both distal and proximal to the 5S rDNA locus

${ }^{A+1}$ aneuploid chromosome set - one extra chromosome

A-1 aneuploid chromosome set - one missing chromosome

(+numeral) number of additional loci acquired by a translocated segment from another haplome

(-numeral) number of loci translocated to another haplome 


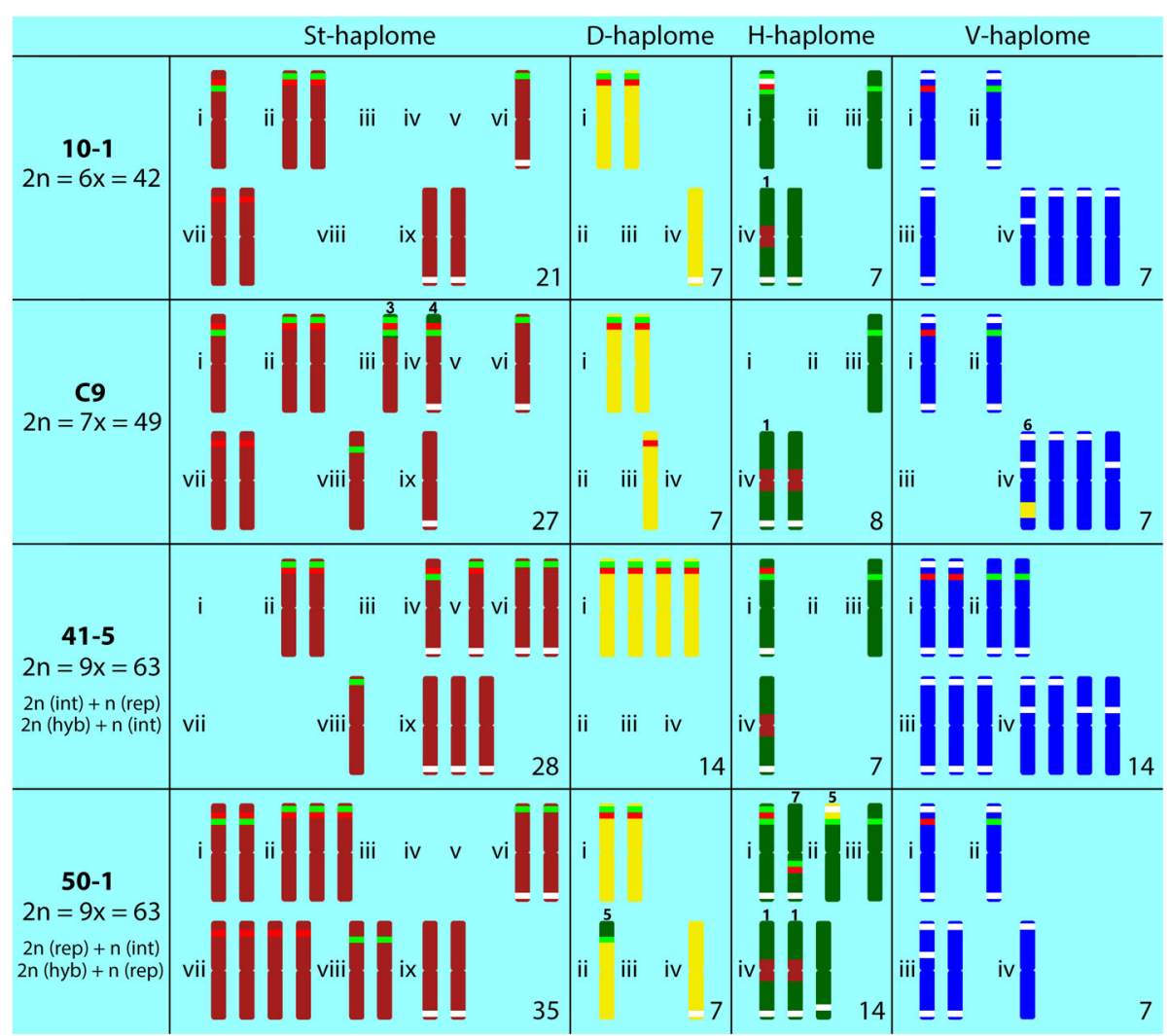

Fig. 3 Schematic patterns of rDNA and pSc119.2 sites revealed in three cytotypes of E. Xmucronata. Only chromosomes exhibiting a signal after FISH are shown. Chromosomes with identical/similar patterns within each haplome are arranged into groups indicated with roman numerals. St haplome - dark red, D haplome - yellow, H haplome - green, V haplome - blue, 5S rDNA - red, 18S rDNA - light green, and pSc119.2 - white. Different types of structural chromosomal alterations are indicated by numerals above the chromosomes (1-7). Total numbers of chromosomes of a particular haplome are given (bottom right side). One Pseudoroegneria chromosome was missing in the analysed metaphase of 41-5

chromosome regions, one chromosome carried two loci on the same chromosome arm; the other chromosomes carried only one site at one chromosome end.

A slightly different pattern was observed in the second hexaploid plant (17-4) upon analyses with FISH with rDNA probes. There were three additional 18S rDNA sites on the Pseudoroegneria-labelled chromosomes and an additional 5S rDNA site on the Aegilops-labelled chromosomes (Fig. 2c and d; Table 2). The obtained results convincingly showed that the hexaploid plants are hybrids between hexaploid $E$. intermedia and E. repens.

\section{Heptaploid Elytrigia xmucronata \\ Genome composition}

The two heptaploid $(2 \mathrm{n}=7 \mathrm{x}=49)$ E. $\times$ mucronata plants C9 and C25B, both from the locality 'Čertoryje' (Table 1 ), were analysed. The probe hybridisation patterns after GISH slightly differed between the two examined heptaploids. In addition, $28 \mathrm{St}+7 \mathrm{H}+7 \mathrm{D}+7 \mathrm{~V}$ chromosomes were found in plant C25B (Fig. 4a), whereas plant C9 exhibited $27 \mathrm{St}+8 \mathrm{H}+7 \mathrm{D}+7 \mathrm{~V}$ chromosomes (Fig. 4c). Similar to the hexaploids, five of the Dasypyrum-labelled chromosomes lacked a probe signal in centromeric regions. Several translocations involving all four haplomes were detected in both examined plants. The translocations are described in a separate chapter (see below).

\section{Chromosomal structural variation}

The contribution of additional chromosomes compared to the hexaploids is reflected by the increased numbers and altered patterns of the chromosomes marked by repetitive probes. There were differences between the two examined heptaploids regarding the Pseudoroegneria and Hordeum chromosome sets. The patterns within the other two haplomes were identical in both plants (although pSc119.2 was not applied in C25B).

The heptaploid C25B, which carries euploid chromosome sets for each haplome, exhibited twelve and thirteen $5 \mathrm{~S}$ and $18 \mathrm{~S}$ rDNA sites, respectively (Fig. 4b; Table 2). The heptaploid $C 9$ exhibited eleven $5 \mathrm{~S}$ and twelve $18 \mathrm{~S}$ rDNA sites (Fig. 4d; Table 2). The differences between the two examined heptaploids are due to the acquisition of one extra Hordeum-like chromosome and the loss of one Pseudoroegneria-like chromosome in C9. 

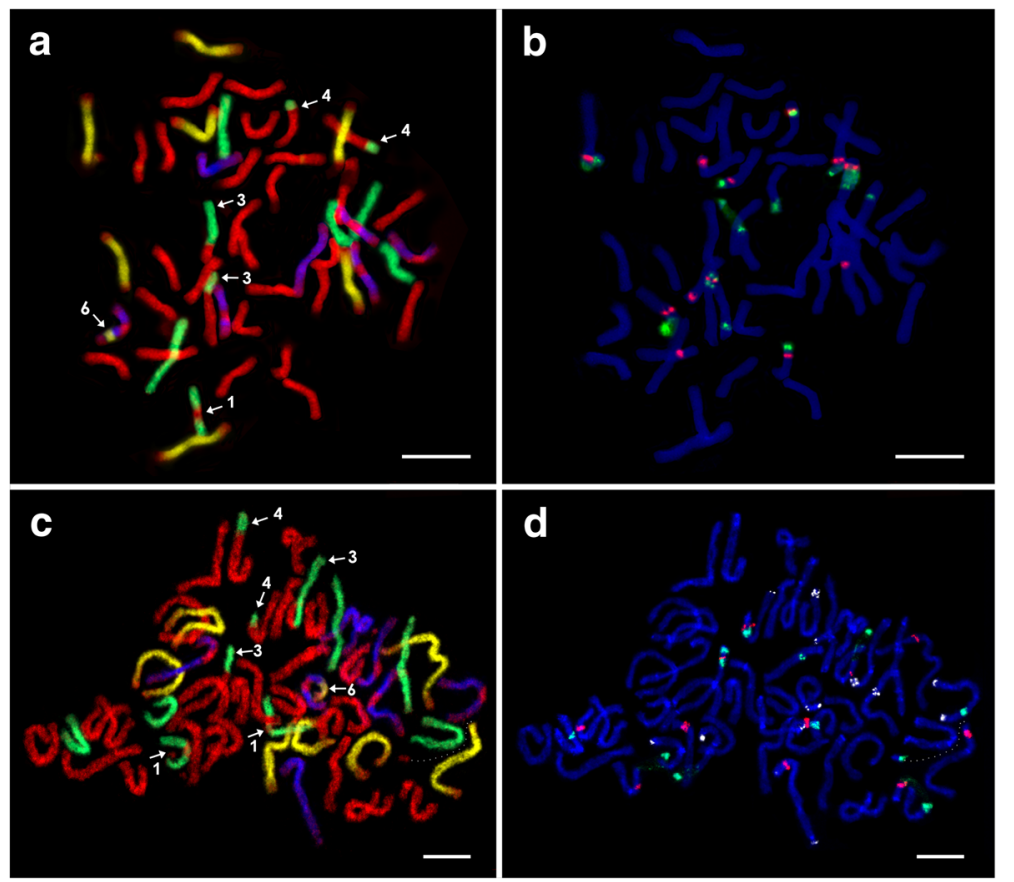

Fig. 4 Mitotic metaphase chromosomes of heptaploid E. xmucronata after sequential FISH and GISH experiments. a and c GISH in plants C25B and C9: Aegilops tauschii (digoxigenin, anti-DIG-FITC, yellow pseudocolour), Dasypyrum villosum (biotin, streptavidin-Cy3, blue pseudocolour), Hordeum bogdanii (biotin, streptavidin-Cy3, green pseudocolour), and Pseudoroegneria spicata (Cy5, red). b and d FISH in plants C25B and C9: 5S rDNA (Cy5, red), 185 rDNA (digoxigenin, anti-DIG-FITC, green), and pSC119.2 (Cy3, white pseudocolour - applied only in C9 - d). After FISH, chromosomes were counterstained with DAPI. Different types of structural chromosomal alterations are indicated with numerals $(1,3,4,6)$. The chromosomal segment broken from the Aegilops chromosome is connected by a dotted line ( $c$ and d). Scale bars $=10 \mu \mathrm{m}$

Thus, in the C25B plant, the Pseudoroegneria chromosomes harboured eight $5 \mathrm{~S}$ sites and nine $18 \mathrm{~S}$ rDNA sites, while seven and eight corresponding sites were found in the C9 plant. The number of pSc119.2 sites on the Pseudoroegneria chromosomes in C9 remained the same as in the hexaploid (3 sites on 3 chromosomes). Two chromosomes exhibited the same pSc119.2 pattern observed in the hexaploid. The third chromosome, which displayed a pSc119.2 site on one chromosome arm, also exhibited a co-localised rDNA locus adjacent to the translocated terminal segment from a Hordeum chromosome on the opposite chromosome arm (Figs. 3 and $4 \mathrm{c}$ and d; Table 2).

The D haplome from Aegilops exhibited two chromosomes with co-localised $5 \mathrm{~S}$ and $18 \mathrm{~S}$ rDNA sites (5S situated proximally); moreover, there was an additional $5 \mathrm{~S}$ site in the terminal region of one chromosome. No pSc119.2 sites were detected in the D haplome (in plant $\mathrm{C} 9$ ). The co-localised 18S-5S-18S locus, which was observed within the Hordeum haplome in hexaploids, was translocated to a Pseudoroegneria-like chromosome. Thus, the Hordeum haplome of the heptaploids carried only a single $18 \mathrm{~S}$ rDNA site. However, the pSc119.2 locus residing within the original 18S-5S-18S rDNA locus in Hordeum was no longer detected within the translocated locus in Pseudoroegneria.
The Dasypyrum-like chromosome set (in plant C9) harboured the same number of rDNA loci found in the hexaploids (one $5 \mathrm{~S}$ and one $18 \mathrm{~S}$ rDNA locus on separate chromosomes) but exhibited only nine pSc119.2 sites on six chromosomes (Figs. 3 and 4d, Table 2).

\section{Nonaploid Elytrigia xmucronata Genome composition}

Three nonaploid $(2 \mathrm{n}=9 \mathrm{x}=63)$ E. $\times$ mucronata plants from two localities were analysed (Table 1). We chose plants with two different assumed origin scenarios for the analyses. While plants $50-1$ and 50-7 from locality 'Dolní Dunajovice' may have arisen from a $2 \mathrm{n}($. repens $)+\mathrm{n}(E$. intermedia $)$ or $2 \mathrm{n}(6 \mathrm{x}$ E. xmucronata $)+\mathrm{n}($ E. repens $)$ combination, the nonaploid 41-5 from locality 'Hovorany' may be characterised by either a $2 \mathrm{n}(E$. intermedia $)+\mathrm{n}(E$. repens $)$ or $2 \mathrm{n}(6 \mathrm{x}$ E. $\times$ mucronata $)+\mathrm{n}($ E. intermedia $)$ gamete composition [16].

There were two clear-cut GISH patterns among the analysed nonaploids, which likely reflected their distinct origins (see also Discussion). Two plants from one population (501 and 50-7) exhibited a $35 \mathrm{St}+14 \mathrm{H}+7 \mathrm{D}+7 \mathrm{~V}$ constitution (Fig. 5a and c). We again encountered a lack of signal from the Dasypyrum probe in the centromeric regions of 

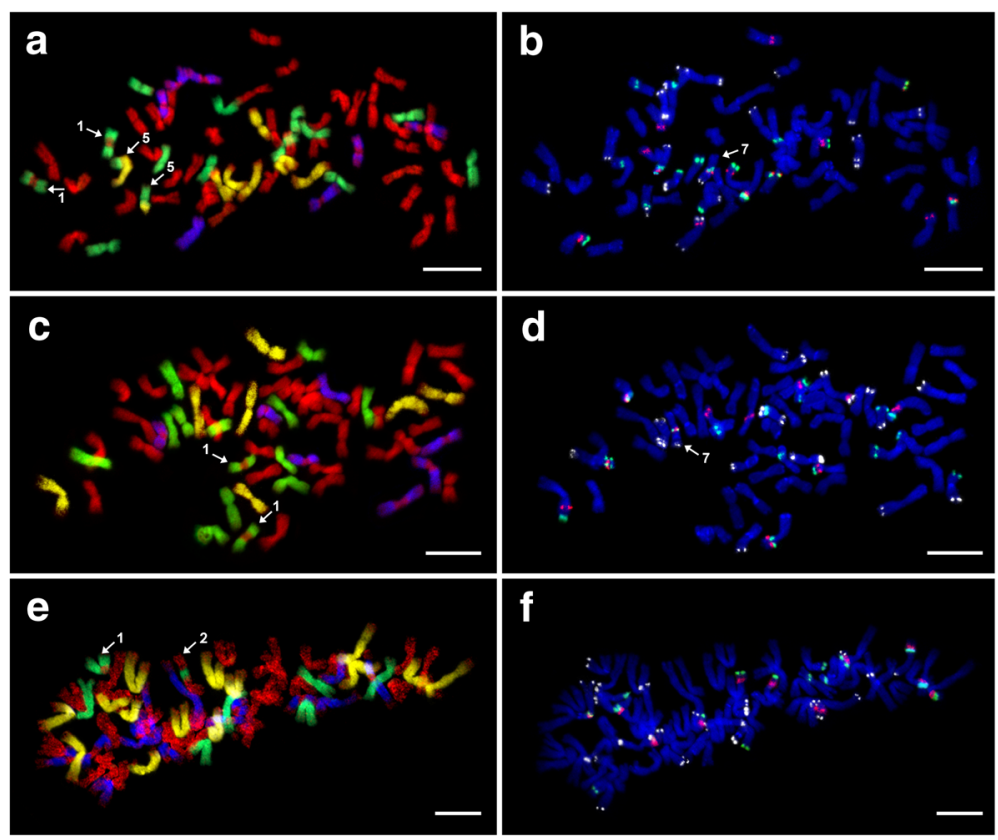

Fig. 5 Mitotic metaphase chromosomes of nonaploid E. Xmucronata after sequential FISH and GISH experiments. a, c. and e GISH in plants 50-1, 50-7 and 41-5 (metaphase only with 62 chromosomes): Aegilops tauschii (digoxigenin, anti-DIG-FITC, yellow pseudocolour), Dasypyrum villosum (biotin, streptavidin-Cy3, blue pseudocolour), Hordeum bogdanii (biotin-streptavidin-Cy3, green pseudocolour), and Pseudoroegneria spicata (Cy5, red). b, d and $\mathbf{f}$ FISH in plants 50-1, 50-7 and 41-5 (metaphase only with 62 chromosomes): $5 S$ rDNA (Cy5, red), 185 rDNA (digoxigenin, anti-DIG-FITC, green), and pSc119.2 (Cy3, white pseudocolour). After FISH, chromosomes are counterstained with DAPI. Different types of structural chromosomal alterations were indicated with numerals $(1,2,5,7)$. Scale bars $=10 \mu \mathrm{m}$

Dasypyrum-labelled chromosomes. Chromosomal translocations were detected in both plants (for details, see below).

The genomic constitution of the 41-5 plant was different from that of the above-described plants (Fig. 5e). Based on the GISH analysis, 41-5 exhibited $28 \mathrm{St}+7$ $\mathrm{H}+14 \mathrm{D}+14 \mathrm{~V}$ chromosomes. Similar to the other analysed plants, the Dasypyrum-labelled chromosomes lacked a signal in centromeric regions.

\section{Chromosomal structural variation}

The examined nonaploid plants showed variable patterns in the FISH analysis, reflecting their distinct origins and genome additivity (50-1 and 50-7 vs. 41-5). Furthermore, differences in the FISH patterns were observed between two plants with an identical genomic constitution (50-1 and 50-7). In this case, the differences were mainly due to polymorphisms within the chromosome sets originating from Pseudoroegneria. Compared with the hexaploids, there was an increase in the total number of all FISH probes in all examined nonaploids (Table 2).

Plant 50-1 harboured a total of fourteen 5S and eighteen 18S rDNA sites. The pSc119.2 probe hybridised to 21 sites on 16 chromosomes. Five chromosome sets from the Pseudoroegneria St haplome exhibited nine $5 \mathrm{~S}$ and nine $18 \mathrm{~S}$ rDNA sites. These rDNA sites co-localised on five chromosomes, while four chromosomes harboured solitary $5 \mathrm{~S}$ rDNA sites, and four other chromosomes harboured solitary 18S rDNA sites (two interstitial and two subtelomeric sites). The St haplome carried four pSc119.2 loci in the terminal chromosome region, two of which resided on $18 \mathrm{~S}$ rDNA-carrying chromosomes on opposite chromosome arms. The Aegilops-like D haplome carried two 5S rDNA sites, three 18S rDNA sites and one pSc119.2 site. Two $5 \mathrm{~S}$ and five $18 \mathrm{~S}$ rDNA sites were detected within the two Hordeum chromosome sets. The $5 \mathrm{~S}$ and $18 \mathrm{~S}$ rDNA loci co-localised on two chromosomes. In addition to the 18S-5S-18S rDNA locus observed in both the hexaploids and heptaploids, there was an additional co-localised 5S$18 \mathrm{~S}$ rDNA locus residing on the same chromosome arm as the $\mathrm{pSc} 119.2$ site. In total, six $\mathrm{pSc119.2}$ sites were located on six Hordeum chromosomes. One of the sites resided on the terminal chromosome segment originating from an Aegilops-like chromosome. Similar to the hexaploids, the V haplome from Dasypyrum harboured solitary 5S and $18 \mathrm{~S}$ rDNA sites located on separate chromosomes. Five out of seven Dasypyrum-like chromosomes carried ten pSc119.2 loci (Figs. 3 and 5b; Table 2).

Plant 50-7 harboured eleven 5S and sixteen $18 \mathrm{~S}$ rDNA sites. The pSc119.2 probe hybridised at 20 sites on 15 chromosomes. The FISH pattern was similar to that of plant 50-1, with major differences present within the Pseudoroegneria-like chromosomes. These chromosome sets carried five $5 \mathrm{~S}$ sites and eight $18 \mathrm{~S}$ rDNA sites. Furthermore, the Aegilops-like chromosomes bore three 
5S sites instead of two; two 18S rDNA loci instead of three; and two pSc119.2 hybridisation sites. The rDNA-FISH patterns within the haplomes from Hordeum and Dasypyrum were otherwise identical in the two plants. Five pSc119.2 loci were found on five Hordeum-labelled chromosomes. The number and pattern of pSc119.2 loci were the same in the Dasypyrum chromosome set (Fig. 5d; Table 2).

For plant 41-5, 28 Pseudoroegneria-labelled chromosomes carried four $5 \mathrm{~S}$ and seven $18 \mathrm{~S}$ rDNA sites. All of the $5 \mathrm{~S}$ rDNA sites co-localised with $18 \mathrm{~S}$ rDNA sites, and three of them were located proximal to $18 \mathrm{~S}$ rDNA. The other 18S rDNA sites resided on three chromosomes in terminal regions. There were seven pSc119.2 loci located in terminal regions, four of which were located on rDNA-carrying chromosomes.

The Hordeum haplome of the nonaploid 41-5 carried one co-localised locus with a proximal $18 \mathrm{~S}$ site and a distal $5 \mathrm{~S}$ rDNA site, residing on the opposite chromosome arm to the pSc119.2 site. Moreover, there was a single $18 \mathrm{~S}$ locus on a separate chromosome. The rDNA loci in both the D and V haplomes exhibited twice the number of sites found within these haplomes in the hexaploids. The D haplome carried two pairs of chromosomes with co-localised $5 \mathrm{~S}$ and $18 \mathrm{~S}$ rDNA sites, and the V haplome from Dasypyrum carried two $5 \mathrm{~S}$ and two $18 \mathrm{~S}$ sites, all of which resided on separate chromosomes. While the V haplome harboured seventeen pSc119.2 sites on 11 chromosomes, no pSc119.2 sites were detected within the D haplome (Figs. 3 and 5f; Table 2).

\section{Chromosomal alterations - overview}

Seven types of structural alterations and one numerical alteration occurred in the three E. xmucronata cytotypes. The following structural alterations were found (Table 3). (1) H/St translocation of a Pseudoroegneria-derived centromeric chromosomal segment to a Hordeum chromosome, which occurred in all the analysed plants (twice in C9, 501 and 50-7) (Figs. 2a, c, 4a, c and 5a, c and e) and was the only type out of the seven that has also been detected in either parental species of $E$. xmucronata (the translocation was detected on a pair of chromosomes in E. repens [18]).
Thus, this translocation is supposed to be inherited from a parent (see Discussion). The translocated chromosome carried a pSc119.2 site in the terminal region of one chromosome arm (when this probe was used). (2) $\mathrm{H} / \mathrm{St}$ translocation, in which a Pseudoroegneria-labelled chromosome carried a Hordeum probe signal in its centromeric region, and this translocation only occurred in the nonaploid 41-5 (Fig. 5e). (3) H/St translocation occurred between terminal parts of the Hordeum and Pseudoroegneria chromosomes. Since the translocation caused acquisition of the co-localised $18 \mathrm{~S}-5 \mathrm{~S}-18 \mathrm{~S}$ rDNA site by a Pseudoroegneria chromosome (Figs. 3 and 4) and disappearance of this site in Hordeum, we classified this translocation as reciprocal, and it occurred in both heptaploids (Fig. 4a and c). (4) H/St terminal translocation occurred when a Pseudoroegneria-like chromosome carried a terminal segment translocated from a Hordeum-like chromosome. This type of translocation occurred only in the heptaploids on two chromosomes (Fig. 4a and c). One of the chromosomes carried a co-localised 5S-18S rDNA site adjacent to the breakpoint and a pSc119.2 site in the terminal region of the opposite chromosome arm (pSc119.2 was applied only in C9). (5) D/H reciprocal translocation of a chromosome segment occurred between Hordeum- and Aegilops-like chromosomes. The breakpoints on both involved chromosomes were close to an $18 \mathrm{~S}$ rDNA site, and the translocated segment of the Aegilops chromosome included a pSc119.2 site, and it was specific to the nonaploid 50-1 (Figs. 3 and 5a). (6) $\mathrm{D} / \mathrm{V}$ interstitial translocation is a non-reciprocal translocation of a chromosomal segment from an Aegilops-like chromosome to a Dasypyrum-like chromosome. The translocated chromosome carried two pSc119.2 sites (in interstitial and subtelomeric positions) and was found in both heptaploid plants (Fig. 4a and c). (7) Inversion within a Hordeum-labelled chromosome, where the co-localised 5S-18S rDNA locus was in a mutually inverted position in nonaploid plants $50-1,50-7$ in comparison to 41-5 (the rDNA locus occurred on the same and opposite chromosome arms, respectively; Figs. 3 and $5 b, d$ and $f$ ).

A numerical chromosomal alteration was observed in one heptaploid plant (C9). Although the total number of

Table 3 Characterisation and occurrence of structural chromosomal alterations in the analysed plants and parental species

\begin{tabular}{|c|c|c|c|c|c|c|c|c|c|c|c|c|}
\hline No. & $\begin{array}{l}\text { Type of chromosomal } \\
\text { alteration }\end{array}$ & $\begin{array}{l}\text { Involved } \\
\text { haplomes }\end{array}$ & $\begin{array}{l}\text { Chromosomal } \\
\text { segment }\end{array}$ & $10-1$ & $17-4$ & C9 & C25B & $41-5$ & $50-1$ & $50-7$ & E. repens & E. intermedia \\
\hline 1 & translocation & $\mathrm{H} / \mathrm{St}$ & centromeric & 1 & 1 & 2 & 1 & 1 & 2 & 2 & 2 & - \\
\hline 2 & translocation & $\mathrm{H} / \mathrm{St}$ & centromeric & - & - & - & - & 1 & - & - & - & - \\
\hline 3 & translocation & $\mathrm{H} / \mathrm{St}$ & terminal & - & - & 1 & 1 & - & - & - & - & - \\
\hline 4 & translocation & $\mathrm{H} / \mathrm{St}$ & terminal & - & - & 2 & 2 & - & - & - & - & - \\
\hline 5 & translocation & $\mathrm{D} / \mathrm{H}$ & terminal & - & - & - & - & - & 1 & - & - & - \\
\hline 6 & translocation & $\mathrm{D} / \mathrm{N}$ & interstitial & - & - & 1 & 1 & - & - & - & - & - \\
\hline 7 & inversion (pericentric) & $\mathrm{H}$ & interstitial & - & - & - & - & - & 1 & 1 & - & - \\
\hline
\end{tabular}


chromosomes in this plant was euploid, not all chromosome sets exhibited multiples of seven chromosomes. One missing chromosome from the Pseudoroegneria chromosome set was compensated by an extra chromosome from Hordeum. The identity of the extra and missing chromosomes was traceable based on comparison with the second heptaploid; the extra Hordeum chromosome was one of the two chromosomes with the translocated centromeric region from Pseudoroegneria, although one Pseudoroegneria-like chromosome carrying a co-localised locus for $5 \mathrm{~S}$ and $18 \mathrm{~S}$ rDNA was missing (Fig. 4c and d; Table 3).

\section{Discussion}

The occurrence of natural hybrids with high ploidy levels has rarely been documented for hybrid complexes from the Triticeae tribe. For example, there are reports of a heptaploid hybrid between Thinopyrum junceum and Elytrigia repens from Sweden [30] and a nonaploid hybrid of Elytrigia pycnantha and E. repens from France [31]. GISH analysis of the latter hybrid revealed the presence of four haplomes within this nonaploid, which consisted of four chromosome sets from Pseudoroegneria, two chromosome sets from Agropyron, two chromosome sets from Thinopyrum and one chromosome set from Hordeum. These results demonstrate that regular meiosis in higher polyploids may occur in hybrid complexes within Triticeae. However, to the best of our knowledge, the presence of four haplomes has not been shown in hexaploid and heptaploid natural hybrids.

In this study, we show that Elytrigia $\times$ mucronata is an allopolyploid of high complexity, in which all three studied hybrid cytotypes comprised all four haplomes (D, H, St, V) present in the parental species E. repens and $E$. intermedia. In all but one case (see below), all of the chromosome sets in the hybrids were euploid and consisted of seven chromosomes. While the genomic constitution (i.e., the type and number of specific haplomes/ basic genomes) of the $E$. xmucronata hybrids reflects the ploidy level of particular cytotypes, it also depends on the type of gametes involved in the origination of particular plants.

If we assume that regular meiosis occurs in the parental species, then the E. xmucronata hexaploid would harbour three chromosome sets from Pseudoroegneria and one chromosome set each from Hordeum, Aegilops and Dasypyrum (genomic formula StStStHDV). In addition to these chromosome sets, the heptaploid cytotype harboured an additional chromosome set from Pseudoroegneria (StStStStHDV). The genomic constitution of the nonaploid cytotypes differed between plants. Two plants exhibited $35 \mathrm{St}+14 \mathrm{H}+7 \mathrm{D}+7 \mathrm{~V}$ chromosomes, while the other nonaploid harboured $28 \mathrm{St}+7$ $\mathrm{H}+14 \mathrm{D}+14 \mathrm{~V}$ chromosomes. We assume that this difference reflects the distinct origins of the nonaploid cytotypes [16] (see below).

\section{Origin of different cytotypes}

The genomic constitutions of the analysed plants allowed us to partly infer the types of gametes that gave rise to their origination (Fig. 6). The hexaploid cytotype of $E$. $\times$ mucronata most likely originated through the merging of two reduced gametes from both parental species.

As mentioned above, nonaploid plants most likely originated through the fusion of reduced and unreduced gametes [15, 16]. Mahelka et al. [16] suggested different scenarios for the origin of the hybrid nonaploids 50-1, 50-7 and 41-5 (plants N7, N6 and N8 in the original article). While plants $50-1$ and $50-7$ may have arisen from $2 \mathrm{n}$ (E. repens) $\mathrm{n}$ (E. intermedia) or 2n $(6 \mathrm{x}$ E. ×mucronata $)+\mathrm{n}$ (E. repens) combinations, nonaploid 41-5 may represent either $2 \mathrm{n}$ ( $E$. intermedia $)+\mathrm{n}($ E. repens $)$ or $2 \mathrm{n}(6 \mathrm{x} E . \quad \times$ mucronata $)+\mathrm{n}$ (E. intermedia) gamete compositions. Since the alternative gamete combinations result in the same genomic compositions, we are not able to discern which scenario truly led to the formation of the analysed nonaploids by using GISH. The involvement of hexaploid E. xmucronata hybrids in the formation of the nonaploids seems to be more likely because hybrids might more easily produce unreduced gametes than pure species due to disturbed meiosis [9]. The heptaploid cytotype likely resulted from heteroploid hybridisation; however, the exact mode of its origination is difficult to determine. One possibility is that the heptaploid originated after a cross between a hexaploid and an octoploid $(2 \mathrm{n}=8 \mathrm{x}=56)$. If the hexaploid parent was either E. repens or E. intermedia (gamete $n=3 \mathrm{x}=21=$ StStH or StDV, respectively), then the gamete from the octoploid would have to have been $n=4 \mathrm{x}=28=$ $\mathrm{StStDV}$ or StStStH, respectively (Fig. 6). However, no octoploid plants have been recorded from this locality. Alternatively, the heptaploids could have originated after a cross between a hexaploid and a nonaploid, in which the latter was the donor of the gamete comprising four chromosome sets. Such a scenario has been observed in Elytrigia wheatgrasses, where a heptaploid plant was found among progeny of the nonaploid hybrid 50-1 collected in the field [16]. It is likely that the pollen donor was either E. repens or E. intermedia. Unfortunately, the genomic constitution of this particular heptaploid was not analysed.

\section{Chromosomal alterations in E. xmucronata}

Chromosomal alterations occurred in all three cytotypes and involved all four haplomes. Most of the translocations involved St and $\mathrm{H}$ chromosomes, while the V chromosome from Dasypyrum was involved in only one 


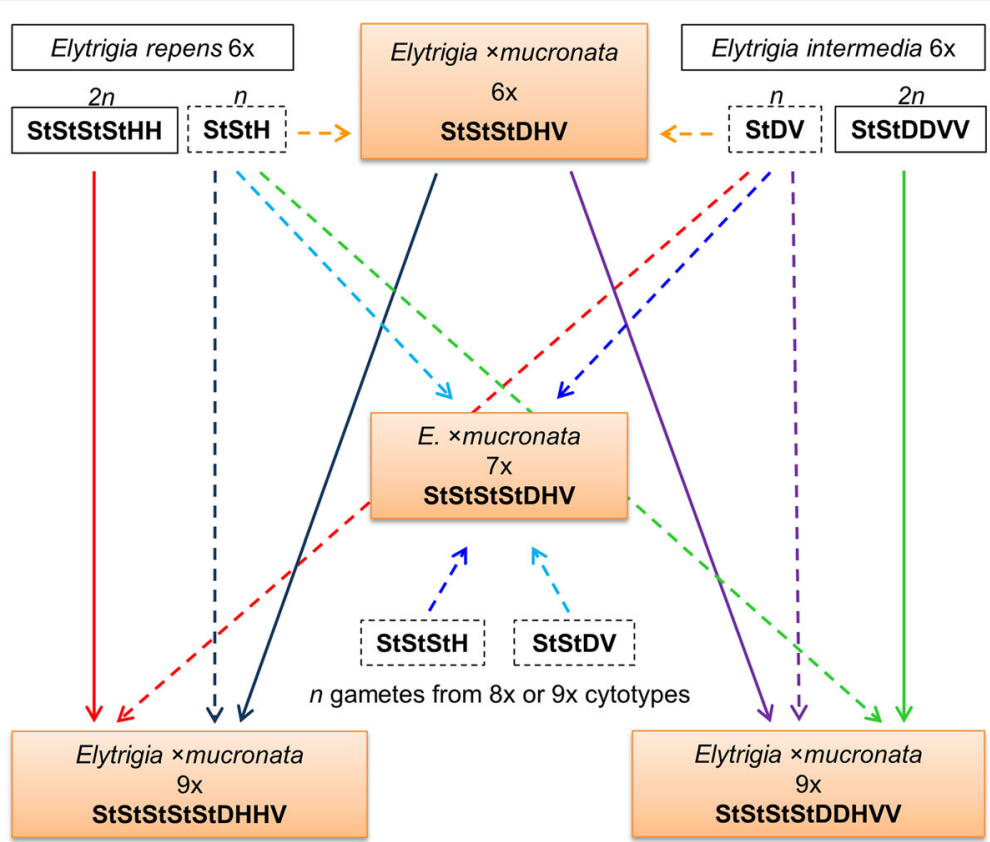

Fig. 6 Proposed scenarios of the origination of $E$. xmucronata cytotypes. The analysed cytotypes $(6 x, 7 x, 9 x)$ are presented in coloured boxes; for each cytotype, the genomic formula is given. For parental species, the contributions of unreduced ( $2 n$, solid boxes) and reduced ( $n$, dashed boxes) gametes are considered. The contributions of unreduced and reduced gametes are indicated with solid and dashed arrows, respectively. Arrows of the same colour represent one potential scenario

translocation. The question is whether this difference simply occurred because St and $\mathrm{H}$ chromosomes outnumber chromosomes from the other haplomes, or if it stems from different levels of karyotype stability, which may have a strong effect on chromosome restructuring and aneuploidy in Triticeae [32].

Structural chromosomal alterations have been reported in other perennial species harbouring an $\mathrm{H}$ and/or St haplome. Dou et al. [33] found two types of non-reciprocal translocations between $\mathrm{H}$ and St haplomes and two types of reciprocal translocations between $\mathrm{H}$ and $\mathrm{Y}$ haplomes in Elymus nutans $(2 \mathrm{n}=6 \mathrm{x}=42$, StStHHYY). Different frequencies of chromosomal alterations between particular haplomes were observed in Kengyilia thoroldiana $(2 \mathrm{n}=$ $6 \mathrm{x}=42$, StStPPYY). The frequency of $\mathrm{P} / \mathrm{Y}$ translocations was higher than that of $\mathrm{P} / \mathrm{St}$ translocations, while no translocations were observed between the chromosomes of the St and Y haplomes [34].

The question arises of how frequently and at which stage of hybrid formation do translocations occur? Without knowledge on the parental species, it is problematic to infer whether particular structural rearrangements have been inherited from the parental species, or whether they have originated de novo in hybrids. Cytogenetic analyses of local accessions of parental species E. intermedia and E. repens showed that in E. repens, one pair of Hordeum chromosomes carried a centromeric H/St 'translocation' [18], corresponding to what we called Type 1 translocation here. In contrast, no translocation that would resemble those observed in the $E$. xmucronata plants analysed here were observed in the other parental species E. intermedia [19, 23]. Therefore, we concluded that all but one (type 1) chromosomal alterations in the three cytotypes of $E$. xmucronata appeared during hybrids' formation.

In any case, the presence of only one such translocation in the hexaploid hybrid indicates the occurrence of regular meiosis in the E. repens parent. Thus, it appears that no de novo translocations appeared in the $E$. $\times$ mucronata hexaploid. The presence of two such translocations in two nonaploids (50-1 and 50-7) and one translocation in the other nonaploid (41-5) is consistent with both alternative origins of these nonaploids.

Furthermore, the presence of the $\mathrm{D} / \mathrm{H}$ reciprocal translocation (type 5) in the nonaploid 50-1 indicates that this plant is not a primary nonaploid hybrid between $E$. intermedia and $E$. repens, since recombination between $\mathrm{H}$ and $\mathrm{D}$ haplomes (which do not co-exist in any of the parents) must have occurred in the hybrid plant. Therefore, an origin involving a 2n (6x E. xmucro$n a t a)+\mathrm{n}($. repens $)$ combination seems more likely in this plant.

The notably higher frequency of chromosomal alterations observed in heptaploid plants contrasted with the results for the other analysed cytotypes. Three of the 
four types of translocations (types 3, 4, and 6) were not found in other cytotypes, suggesting that several multivalents between homoeologous chromosomes must have occurred during the formation of the gametes, giving rise to the heptaploid plants.

The concurrent presence of both chromosomes with reciprocally translocated segments indicates alternate segregation (i.e., the translocated chromosomes do not segregate and are present in a single gamete). It is unlikely that this state originated from the fusion of two unbalanced gametes. Non-reciprocal translocations can be non-reciprocal per se or may result from adjacent segregation, where normal and translocated chromosomes segregate into one gamete [35].

Moreover, the numerical chromosomal alteration observed in one heptaploid plant was an example of hidden aneuploidy [27, 32], i.e., the absence of one chromosome is compensated by the acquisition of an extra chromosome from another chromosome set.

Chromosomes were also observed carrying differentiating signals in the centromeric regions in Dasypyrum-like chromosomes. This feature has previously been reported for E. intermedia species [19, 23]. Further research is required to reveal the true nature of these GISH patterns and determine whether they resulted from chromosome restructuring or sequence homology.

\section{Mapping of repetitive DNA in E. xmucronata hybrids}

The evolution of ribosomal DNA genes in relation to allopolyploidy is an intensively studied issue (e.g., [36, 37]). rDNA loci are valuable chromosome markers, and the mapping of rDNA loci using in situ hybridisation allows for the evaluation of the progenitor-derivative patterns and positional dynamics of ribosomal loci within allopolyploid genomes. rDNA genes in allopolyploid species may experience contrasting and barely predictable patterns of evolution, ranging from loss of some loci with respect to their progenitors (Zingeria-[38]) over nearly complete additivity (e.g., Thinopyrum ponticum-[39]; Nicotiana-[40]) to increasing the number of rDNA loci (Triticum-[41]). Triticeae grasses are characterised by the ability to change the positions of rDNA loci [42-44], which may occur via the dispersion of minor loci, followed by rDNA array magnification and deletion of the original loci thereafter. Loss of rDNA loci is one potential mechanism accelerating the process of concerted evolution [45].

In all investigated hybrid cytotypes, the $5 \mathrm{~S}$ and $18 \mathrm{~S}$ rDNA loci were located on all chromosome sets representing the different haplomes. Therefore, the rDNAs of the $E$. $\times$ mucronata hybrid reflect the principle of genome additivity to a certain degree. However, because $E$. xmucronata is a hybrid between two allopolyploid species, the dynamics of the rDNA loci of this hybrid are traceable, provided that the pattern in both parental species is understood. Thus, we characterised specimens of both $E$. repens and $E$. intermedia from the same distribution area from which the hybrids originated ([18, 23], Mahelka, Kopecký, unpubl. data). In both parental species, we encountered some reorganisation of rDNA loci with respect to their diploid progenitors, which likely occurred following the origination of the allopolyploids (for discussion, see [18, 23]). The patterns of the rDNA loci of both E. repens and E. intermedia are shown in Additional file 1: Table S1. Notably, severe elimination of all but one minor $45 \mathrm{~S}$ rDNA locus likely occurred within the Hordeum subgenome in E. repens (genomic formula StStStStHH). Similarly, the elimination of some 45S rDNA loci occurred within the Pseudoroegneriaand Dasypyrum-like subgenomes in E. intermedia (genomic formula StStDDVV). In both species, 5S rDNA was less heavily affected by the loss of the loci than $45 \mathrm{~S}$ rDNA.

In this study, we predicted the theoretical numbers of rDNA loci in hybrid E. xmucronata cytotypes (Additional file 1: Table S1) by assuming complete additivity of the parental rDNA loci. From comparison of the observed data, we can infer the positional dynamics of rDNA loci in the hybrids. For this purpose, we consider the $18 \mathrm{~S}$ and $45 \mathrm{~S}$ probes to be equally informative.

The total numbers of 5S rDNA loci fell well into the expected numbers in all hybrid plants examined. In the nonaploid $41-5$, the number of $5 \mathrm{~S}$ rDNA loci only fell within the expected range if the [2n (6x E. ×mucro$n a t a)+\mathrm{n}($ E. intermedia $)]$ scenario of its origin was considered. Under the opposite scenario $[2 \mathrm{n}$ (E. intermedia $)+\mathrm{n}$ (E. repens)], a lower number was observed (11 vs. 13-15 expected). This depletion was mainly caused by a smaller number of $5 \mathrm{~S}$ rDNA sites on Pseudoroegneria chromosomes than expected (4 sites observed vs. 6-7 expected). However, we must note that the real number of loci in this plant may be higher than was observed because one chromosome was missing in the analysed metaphases. Such an observation is otherwise in agreement with the pattern found for $5 \mathrm{~S}$ rDNA loci in the parental species, in which no major changes in the 5S rDNA loci were recorded ([23], unpubl. data).

In contrast, the total numbers of $18 \mathrm{~S}$ rDNA sites were always higher than expected in the hybrids of all analysed cytotypes. This observation is especially interesting if we consider that severe losses of $45 \mathrm{~S}$ rDNA loci had already occurred in both parental species $[18,23]$. Restoration of some loci clearly occurred within the Hordeum and, to a lesser degree, Pseudoroegneria haplomes (see hexaploid 10-1) after the hybridisation events. In particular, while examining the Hordeum haplome, we observed co-localised 5S-18S and/or 18S-5S-18S rDNA loci in all the cytotypes (although in both heptaploids, the co-localised locus had been translocated to a Pseudoroegneria chromosome); however, this locus was not observed in $E$. repens [18]. This pattern was consistent in all three 
cytotypes, but neither the mechanism of the re-appearance of the loci nor its cause was studied.

We did not probe either of the parental species with the pSc119.2 probe. In other studies, up to 5 chromosomes with one or two pSc119.2 loci (located in a terminal or interstitial position) have been found in $E$. intermedia [46]. In E. repens, the total number of pSc119.2 sites ranges between 5 and 10 (one interstitial site and others in the terminal region) [47]. Although these plants come from different geographic regions, it appears that similar to $18 \mathrm{~S} \mathrm{rDNA}$, the total number of pSc119.2 sites detected in E. ×mucronata was higher than that in the parental species.

\section{Conclusions}

Hybridisation and polyploidisation are prominent speciation mechanisms in the grass tribe Triticeae. These mechanisms have not only produced new allopolyploid lineages, but the ongoing transfer of genetic material via extensive hybridisation and introgression may also have significantly enriched the gene pools of the newly established lineages, thus providing raw material for selection. Many Triticeae wheatgrasses, including E. intermedia, represent invaluable in situ sources of genetic material that may be useful for wheat improvement. Therefore, the newly established hybrid lineages are both of interest to general science and of particular concern to wheat breeders due to their potential practical impact. We performed molecular cytogenetic analyses using genomic and fluorescence in situ hybridisation on three cytotypes of the allopolyploid $E$. xmucronata, a hybrid between two allopolyploid wheatgrasses, E. intermedia and $E$. repens. In all three investigated cytotypes (i.e., hexaploid, heptaploid, and nonaploid), we observed coexistence of four different haplomes that occurred in the parental species, thus confirming the assumed hybrid origin of the plants. The genomic constitutions of the analysed plants allowed us to partially infer the types of gametes that gave rise to their origins. While the hexaploid cytotype of $E$. $\times$ mucronata originated through the merging of two reduced gametes from both parental species, the heptaploid cytotype likely resulted from heteroploid hybridisation. The nonaploid plants most likely originated through the fusion of reduced (n) and unreduced ( $2 n$ ) gametes. The different genomic constitutions of the nonaploids showed that along with both parental species, the hexaploid $E$. xmucronata should be considered as a donor of unreduced gametes. Several chromosomal alterations observed in both heptaploid and some nonaploid plants occurred during and/or after the formation of the hybrids. Moreover, a specific chromosomal translocation detected in one of the nonaploids indicated that it was not a primary hybrid. Therefore, at least some of the hybrids are fertile and produce viable offspring.

\section{Methods}

\section{Plant material}

The plant material used in this study is available as living material from previous studies $[15,16]$. All investigated plants were collected by the author (VM) at localities where no permissions were necessary to collect the samples. Details on the sample locations are given in Table 1 and Fig. 1. The experiments were performed on selected hybrid plants and involved two hexaploid $(2 n=6 x=42)$, two heptaploid $(2 \mathrm{n}=7 \mathrm{x}=49)$, and three nonaploid $(2 \mathrm{n}=$ $9 \mathrm{x}=63)$ E. $\times$ mucronata plants (Table 1). Hexaploid and nonaploid plants were used in previous studies focused on genome size variation and natural hybridisation $[15$, 16]. Thus, while hexaploid plants $10-1$ and $17-4$ correspond to accessions $\mathrm{H}-30$ and $\mathrm{H}-2$ from Mahelka et al. [16], nonaploid plants $41-5,50-1$ and 50-7 correspond to nonaploids N8, N7 and N6 from the same study, respectively. The heptaploids are studied for the first time in this study. The seeds of diploid Triticeae species used for probe preparation were provided by the US Department of Agriculture (USDA) National Small Grains Collection.

\section{Collecting materials and slide preparation}

Plants were cultivated in plastic pots filled with perlite in the greenhouse. Root tips were pre-treated in ice cold water for $24-33 \mathrm{~h}$ and fixed in fresh ethanol-acetic acid fixative $(3: 1, \mathrm{v} / \mathrm{v})$.

The fixed root tips were washed in distilled water (twice) and citrate buffer $(0.01 \mathrm{M}$ citric acid and $0.01 \mathrm{M}$ sodium citrate buffer, $\mathrm{pH} 4.8$ ) for 5 min each. Thereafter, the root tips were treated in an enzyme mixture $[1 \%(\mathrm{w} / \mathrm{v})$ pectinase, $1 \%$ $(\mathrm{w} / \mathrm{v})$ pectolyase and $20 \%(\mathrm{v} / \mathrm{v})$ pectinase (Sigma, St. Louis, $\mathrm{MO}$, USA) in citrate buffer] for $3-4 \mathrm{~h}$ at $37^{\circ} \mathrm{C}$. After treatment, the digested tissue was washed in distilled water.

The slides were prepared using the smear method [48] according to a previous report [49] with several modifications. The digested tissue was carefully transferred to a microscope slide, and a suspension was produced with needles. Cold $75 \%$ acetic acid was then immediately added to the suspension, after which the slide was placed on a hot plate and stirred with a needle to spread the cells. Finally, $150 \mu \mathrm{l}$ of cold ethanol-acetic acid fixative was added, and the slides were washed with ethanol and air-dried.

\section{Probe preparation and in situ hybridisation}

The following three probes representing repetitive chromosomal markers were used for the FISH analyses: (1) a $5 \mathrm{~S}$ rDNA probe, (2) an $18 \mathrm{~S}$ rDNA probe, and (3) a pSc119.2 probe. Ribosomal 5S and 18S DNAs were amplified using the primers 5SprobeF (5'-GATCCCATCAGAACTCCGAAG-3'), 5SprobeR (5'-CGGTGCTTT AGTGCTGGTATG-3') [50], 18S-F (5'-CGAACTGTG AAACTGCGAATGGC-3') and 18S-R (5'-TAGG 
AGCGACGGGCGGTGTGTG-3') [51]. The pSc119.2 probe, a 120-bp fragment originally isolated from rye [52], was amplified from Triticum aestivum cv. Chinese Spring DNA according to the reported protocol.

The selection of the diploid species used to obtain the genomic probes was based on analyses of the genomic constitutions of the parental species [18, 19, 23]. Genomic DNAs from the diploid species Aegilops tauschii Coss. (USDA accession identifier PI542278; representing D haplome), Dasypyrum villosum (L.) P. Candargy (PI639751; V haplome), Hordeum bogdanii (PI269406; H haplome), and Pseudoroegneria spicata (Pursh) Á. Löve (PI563869; St haplome) were extracted using the DNeasy Plant Mini Kit (Qiagen, Hilden, Germany). The probes were labelled either via nick translation using the Biotin-Nick Translation Kit and the DIG-Nick Translation Kit (Roche, Indianapolis, IN, USA) according to the manufacturer's protocol, or via random primer labelling [53] with direct fluorochromes (Cy3, Cy5; Amersham, Piscataway, NJ, USA).

The following three sequential in situ experiments were performed on mitotic metaphase chromosomes of $E$. xmucronata: (i) FISH with the probes for 5S rDNA (Cy5), $18 \mathrm{~S}$ rDNA (digoxigenin, anti-DIG-FITC conjugate), and pSc119.2 (Cy3, this probe was not applied in plants 17-4 and $\mathrm{C} 25 \mathrm{~B}$ ); (ii) GISH with three genomic probes, from Aegilops tauschii (digoxigenin, anti-DIG-FITC conjugate), Hordeum bogdanii (biotin, streptavidin-Cy3), and Pseudoroegneria spicata (Cy5); and (iii) GISH with a genomic probe from Dasypyrum villosum (biotin, streptavidin-Cy3). The hybridisation pattern was always confirmed in 3-6 metaphases per plant.

Chromosomes and probes were simultaneously denatured at $93^{\circ} \mathrm{C}$ for 3 min on a hot plate (ThermoBrite ${ }^{\text {Tw }}$ Slide Processing System, StatSpin, Norwood, MA, USA). Hybridisation was then performed at $63^{\circ} \mathrm{C}$ for $3 \mathrm{~h}$ according to the relevant literature $[54,55]$. Detection was completed using an anti-DIG-FITC conjugate (Roche, Indianapolis, IN, USA) or a streptavidin-Cy3 conjugate (Sigma, St. Louis, $\mathrm{MO}$, USA) $\left(1 \mathrm{~h}\right.$ in $\left.37^{\circ} \mathrm{C}\right)$. Slides were mounted with Vectashield antifade mountant (Vector Laboratories, Burlingame, CA, USA), examined and photographed on a Zeiss Axio Imager.Z2 microscope system equipped with an ApoTome.2. Zen (Zeiss, Jena, Germany) and Adobe Photoshop software (Adobe Systems, San Jose, CA, USA) were used for merging and processing the images.

\section{Additional file}

Additional file 1: Table S1. Theoretical patterns of rDNA loci in hexaploid $(2 n=6 x)$, heptaploid $(2 n=7 x)$, and nonaploid $(2 n=9 x)$ cytotypes of $E$. $\times$ mucronata hybrids. Observed values of rDNA loci for the parental species and expected values for the investigated $E$. Xmucronata cytotypes. (XLSX $12 \mathrm{~kb})$

\section{Abbreviations}

18S rDNA: 18S ribosomal DNA; 45S rDNA: 45S ribosomal DNA; 5 S rDNA: $5 S$ ribosomal DNA; anti-DIG-FITC: Anti-digoxigenin-fluorescein isothiocyanate; Cy3: Cy3-dUTP, Cyanine 3-dUTP; Cy5: Cy5-dUTP, Cyanine 5-dUTP; DAPI: 4',6Diamidino-2-phenylindole; DNA: Deoxyribonucleic acid; FISH: Fluorescence in situ hybridisation; GISH: Genomic in situ hybridisation; ITS: Internal transcribed spacer; rDNA: Ribosomal DNA; streptavidin-Cy3: Streptavidincyanine 3

\section{Acknowledgements}

We are grateful to František Krahulec for helpful discussions and comments on the manuscript. We thank Andreas Houben for providing pSc119.2 and Michaela Jandová for help with the preparation of the map. Seeds from the plant accessions used for probe preparation were generously provided by the USDA National Small Grains Collection.

\section{Funding}

The study was financially supported by long-term research development project RVO 67985939 from the Czech Academy of Sciences, project 17-06548S from the Czech Science Foundation (to VM) and project SW 260439 from Charles University.

The funding body had no role in the design of the study and collection, analysis, and interpretation of data and in writing the manuscript.

\section{Availability of data and materials}

All data generated during this study are included in this article (and its supplementary information file).

\section{Authors' contributions}

$A B$ and VM designed the study. LP performed the experiments and analysed the data. $L P, A B$ and VM wrote the manuscript. All authors read and approved the final manuscript.

Ethics approval and consent to participate

Not applicable.

Consent for publication

Not applicable.

\section{Competing interests}

The authors declare that they have no competing interests.

\section{Publisher's Note}

Springer Nature remains neutral with regard to jurisdictional claims in published maps and institutional affiliations.

Received: 1 August 2018 Accepted: 26 April 2019

Published online: 31 May 2019

\section{References}

1. Comai L. The advantages and disadvantages of being polyploid. Nat Rev Genet. 2005;6(11):836-46.

2. Meyers LA, Levin DA. On the abundance of polyploids in flowering plants. Evolution. 2006;60(6):1198-206.

3. Soltis PS, Soltis DE. The role of hybridization in plant speciation. Annu Rev Plant Biol. 2009;60:561-88.

4. Goulet BE, Roda F, Hopkins R. Hybridization in plants: old ideas, new techniques. Plant Physiol. 2017;173(1):65-78.

5. Grant V. Plant speciation. 2nd ed. New York: Columbia University Press; 1981.

6. Wang H, Vieira FG, Crawford JE, Chu C, Nielsen R. Asian wild rice is a hybrid swarm with extensive gene flow and feralization from domesticated rice. Genome Res. 2017:27(6):1029-38.

7. Harlan JR, DeWet J. On Ö. Winge and a prayer: the origin of polyploidy. Bot Rev. 1975:41(4):361-90.

8. Suarez EY, Lopez AG, Naranjo CA. Polyspermy versus unreduced male gametes as the origin of nonaploids (9x) common wheat plants. Caryologia. 1992;45(1):21-8.

9. Ramsey J, Schemske D. Pathways, mechanisms, and rates of polyploid formation in flowering plants. Annu Rev Ecol Syst. 1998;29:467-501. 
10. Doyle JJ, Flagel LE, Paterson AH, Rapp RA, Soltis DE, Soltis PS, et al. Evolutionary genetics of genome merger and doubling in plants. Annu Rev Genet. 2008:42:443-61.

11. Feldman M, Levy A, Chalhoub B, Kashkush K. Genomic plasticity in polyploid wheat. In: Soltis PS, Soltis DE, editors. Polyploidy and genome evolution. Berlin: Springer Berlin Heidelberg; 2012. p. 109-35.

12. Dewey DR. In: Gustafson J, editor. Gene manipulation in plant improvement, Proc 16th Stadler genetic symposium The genomic system of classification as a guide to intergeneric hybridization with the perennial Triticeae. New York: Plenum Press; 1984. p. 209-79.

13. Löve Á. Conspectus of the Triticeae. Fedd Rep. 1984;95:425-521.

14. Soreng RJ, Peterson PM, Romaschenko K, Davidse G, Teisher JK, Clark $L G$, et al. A worldwide phylogenetic classification of the Poaceae (Gramineae) II: an update and a comparison of two 2015 classifications. J Syst Evol. 2017:55(4):259-90.

15. Mahelka V, Suda J, Jarolímová V, Trávníček P. Genome size discriminates between closely related taxa Elytrigia repens and E. intermedia (Poaceae: Triticeae) and their hybrid. Folia Geobot. 2005;40:367-84.

16. Mahelka V, Fehrer J, Krahulec F, Jarolímová V. Recent natural hybridization between two allopolyploid wheatgrasses (Elytrigia, Poaceae): ecological and evolutionary implications. Ann Bot. 2007:100(2):249-60.

17. Mason-Gamer RJ. Allohexaploidy, introgression, and the complex phylogenetic history of Elymus repens (Poaceae). Mol Phylogenet Evol. 2008; 47(2):598-611

18. Mahelka V, Kopecký D. Gene capture from across the grass family in the allohexaploid Elymus repens (L.) Gould (Poaceae, Triticeae) as evidenced by ITS, GBSSI, and molecular cytogenetics. Mol Biol Evol. 2010;27(6):1370-90.

19. Mahelka V, Kopecký D, Paštová L. On the genome constitution and evolution of intermediate wheatgrass (Thinopyrum intermedium: Poaceae, Triticeae). BMC Evol Biol. 2011;11:127.

20. Wang RRC, Lu B. Biosystematics and evolutionary relationships of perennial Triticeae species revealed by genomic analyses. J Syst Evol. 2014;52:697-705.

21. Mason-Gamer RJ. Reticulate evolution, introgression, and intertribal gene capture in an allohexaploid grass. Syst Biol. 2004;53(1):25-37.

22. Mahelka V, Krak K, Kopecký D, Fehrer J, Šafár J, Bartoš J, et al. Multiple horizontal transfers of nuclear ribosomal genes between phylogenetically distinct grass lineages. PNAS. 2017;114(7):1726-31.

23. Mahelka V, Kopecký D, Baum BR. Contrasting patterns of evolution of $45 \mathrm{~S}$ and $5 \mathrm{~S}$ rDNA families uncover new aspects in the genome constitution of the agronomically important grass Thinopyrum intermedium (Triticeae). Mo Biol Evol. 2013;30(9):2065-86.

24. Kishii M, Wang R-C, Tsujimoto H. GISH analysis revealed new aspect of genomic constitution of Thinopyrum intermedium. Czech J Genet Plant Breed. 2005:41:92-5.

25. Ellneskog-Staam P, Salomon B, von Bothmer R, Anamthawat-Jònsson K. Trigenomic origin of the hexaploid Psammopyrum athericum (Triticeae: Poaceae) revealed by in-situ hybridization. Chromosom Res. 2001;9(3):243-9.

26. Chester M, Leitch AR, Soltis PS, Soltis DE. Review of the application of modern cytogenetic methods (FISH/GISH) to the study of reticulation (polyploidy/hybridisation). Genes. 2010;1(2):166-92

27. Chester M, Gallagher JP, Symonds W, Veruska A, Mavrodiev EV, Leitch AR, et al. Extensive chromosomal variation in a recently formed natural allopolyploid species, Tragopogon miscellus (Asteraceae). PNAS. 2012;109(4):1176-81.

28. Weiss-Schneeweiss H, Tremetsberger K, Schneeweiss GM, Parker JS, Stuessy TF. Karyotype diversification and evolution in diploid and polyploid south American Hypochaeris (Asteraceae) inferred from rDNA localization and genetic fingerprint data. Ann Bot. 2008;101(7):909-18.

29. Brasileiro-Vidal AC, Cuadrado A, Brammer SP, Zanatta ACA, Prestes AM, Moraes-Fernandes MIB, et al. Chromosome characterization in Thinopyrum ponticum (Triticeae, Poaceae) using in situ hybridization with different DNA sequences. Genet Mol Biol. 2003;26(4):505-10.

30. Östergren G. Cytology of Agropyron junceum, A. repens and their spontaneous hybrids. Hereditas. 1940;26:305-16.

31. Refoufi A, Jahier J, Esnault MA. Genome analysis of a natural hybrid with $2 \mathrm{n}$ $=63$ chromosomes in the genus Elytrigia Desv. (Poaceae) using the GISH technique. Plant Biol. 2001:3(4):386-90.

32. Zhang H, Bian Y, Gou X, Zhu B, Xu C, Qi B, et al. Persistent wholechromosome aneuploidy is generally associated with nascent allohexaploid wheat. PNAS. 2013;110(9):3447-52.
33. Dou Q-W, Chen Z-G, Liu Y-A, Tsujimoto H. High frequency of karyotype variation revealed by sequential FISH and GISH in plateau perennial grass forage Elymus nutans. Breed Sci. 2009;59(5):651-6.

34. Wang Q, Liu H, Gao A, Yang X, Liu W, Li X, et al. Intergenomic rearrangements after polyploidization of Kengyilia thoroldiana (Poaceae: Triticeae) affected by environmental factors. PLoS One. 2012;7(2):e31033.

35. Schlegel R. Dictionary of plant breeding, vol. 571. Boca Raton: CRC Press; 2009.

36. Volkov R, Komarova N, Hemleben V. Ribosomal DNA in plant hybrids: inheritance, rearrangement, expression. Syst Biodivers. 2007;5(3):261-76.

37. Sochorová J, Coriton $O$, Kuderová A, Lunerová J, Chèvre A-M, Kovař́k A. Gene conversion events and variable degree of homogenization of rDNA loci in cultivars of Brassica napus. Ann Bot. 2017;119(1):13-26.

38. Kotseruba V, Gernard D, Meister A, Houben A. Uniparental loss of ribosomal DNA in the allotetraploid grass Zingeria trichopoda $(2 n=8)$. Genome. 2003;46:156-63.

39. Li D, Zhang X. Physical localization of the 18S-5.8S-26S rDNA and sequence analysis of ITS regions in Thinopyrum ponticum (Poaceae: Triticeae): implications for concerted evolution. Ann Bot. 2002;90:445-52.

40. Kovařík A, Matyášek R, Lim KY, Skalická K, Koukalová B, Knapp S, et al. Concerted evolution of 18-5.8-26S rDNA repeats in Nicotiana allotetraploids. Biol J Linn Soc. 2004:82(4):615-25.

41. Jiang J, Gill BS. New $185 \cdot 265$ ribosomal RNA gene loci: chromosomal landmarks for the evolution of polyploid wheats. Chromosoma. 1994;103(3):179-85.

42. Dubcovsky J, Dvořák J. Ribosomal RNA multigene loci: nomads of the Triticeae genomes. Genetics. 1995;140(4):1367-77.

43. Raskina O, Belyayev A, Nevo E. Quantum speciation in Aegilops: molecular cytogenetic evidence from rDNA cluster variability in natural populations. PNAS. 2004;101(41):14818-23.

44. Raskina O, Barber JC, Nevo E, Belyayev A. Repetitive DNA and chromosomal rearrangements: speciation-related events in plant genomes. Cytogenet Genome Res. 2008;120(3-4):351-7.

45. Eickbush TH, Eickbush DG. Finely orchestrated movements: evolution of the ribosomal RNA genes. Genetics. 2007;175(2):477-85.

46. Georgieva M, Sepsi A, Molnár-Láng M, Tyankova N. Molecular cytogenetic analysis of Triticum aestivum and Thinopyrum intermedium using the FISH technique. C R Acad Bulg Sci. 2011;64(12):1713-8.

47. Ørgaard M, Anamthawat-Jónsson K. Genome discrimination by in situ hybridization in Icelandic species of Elymus and Elytrigia (Poaceae: Triticeae). Genome. 2001;44(2):275-83.

48. Lysák MA, Fransz PF, Ali HB, Schubert I. Chromosome painting in Arabidopsis thaliana. Plant J. 2001;28(6):689-97.

49. Pijnacker LP, Ferwerda MA. Giemsa C-banding of potato chromosomes. Can J Genet Cytol. 1984;26(4):415-9.

50. Shishido R, Sano Y, Fukui K. Ribosomal DNAs: an exception to the conservation of gene order in rice genomes. Mol Gen Genet. 2000;263(4):586-91.

51. Chang K-D, Fang S-A, Chang F-C, Chung M-C. Chromosomal conservation and sequence diversity of ribosomal RNA genes of two distant Oryza species. Genomics. 2010;96(3):181-90.

52. Bedbrook JR, Jones J, O'Dell M, Thompson RD, Flavell RB. A molecular description of telomeric heterochromatin in Secale species. Cell. 1980;19(2):545-60.

53. Schwarzacher T, Heslop-Harrison P. Practical in situ hybridization. 1st ed. Oxford: Bios Scientific Publishers Ltd; 2000

54. Baum BR, Bailey LG, Belyayev A, Raskina O, Nevo E. The utility of the nontranscribed spacer of $5 \mathrm{~S}$ rDNA units grouped into unit classes assigned to haplomes - a test on cultivated wheat and wheat progenitors. Genome. 2004:47(3):590-9.

55. Raskina O, Belyayev A, Nevo E. Activity of the En/Spm-like transposons in meiosis as a base for chromosome repatterning in a small, isolated, peripheral population of Aegilops speltoides Tausch. Chromosom Res. 2004; 12(2):153-61. 